\title{
The Nature of Strategic Management
}

\author{
Branislav Djordjevic \\ Plans are less important than planning! \\ Dale McConkey
}

\begin{abstract}
To define stategic management is very easy. It is an art and science of formulating implementing and evaluating cross-functional decisions that enable an organization to achieve its objecrives. As this definition implies, strategic management focuses on integrating manageemt, marketing, finance/accounting, production/operations, research and development, and computer information systems to achieve organizational success. The strategicmanagement proces consists of tree stages: strategu formulation, strategy implementation, and strategy evaluation. Strategy formulation includes developing a vision and mission, identifying an organization's external opportunities and threats, determining internal strenghts and weaknesses, establishing long-term objectives, generating alternative strategies, and choosing particular strategies to pursue. Strategy implementation requires a firm to establish annual objectives, device policies, motivate employees, and allocate resources so that formulated strategies can be executed. Strategy evaluation is the final stage in stretegic management. Managers desparately need to know when particula strategies are not working well, strategy evaluation is the primary means for obtaining this information. The strategicmanagement process is dynamic and continuous. A change in any of the major components in the model can necessitate in any or all of the other components. International operations can be as simple as exporting a product to a single foreign country or as complex as operating manufacturing, distribution, and marketing facilitatets in many countries. Firms are acquiring foreign companies and forming joint ventur- es with them and vice versa. This trend is accelerating dramatically. International expans- ion is no guarantee of success, however.
\end{abstract}

\section{What is Strategic Management?}

Once there were two company presidents who competed in the same industry. These two presidents decided to go on a camping trip to discuss a possible merger. They hiked deep into the woods. Suddenly, they came upon a grizzly bear that rose up on its hind legs and snarled. Instantly, the first president took off his knapsack and got a pair of jogging shoes. The second president said: "Hey, you can't outrun that bear." The first president responded, "Maybe I can't outrun that bear, but I surely can outrun you!" This story captures the notion of strategic management, which is to achieve and maintain competitive advantage.

\section{Defining Strategic Management}

Strategic Management can be defined as the art and science of formulating, implementing and evaluating cross-functional decisions that enable an organization to achieve its objectives. As this definition implies, strategic management focuses on integrating management, marketing, finance/accounting, production/operations, research and development, and computer information systems to achieve organizational success. The term strategic management is used synonymously with the term strategic planning. The latter term is more often used in the 
business world, whereas the former the is often used in academia. Sometimes the term strategic management is used to refer to strategy formulation, implementation, and evaluation, with strategic planning referring only to strategy formulation. The purpose of strategic management is to exploit and create new and different opportunities for tomorrow; longrange planning, in contrast, tries to optimize for tomorrow the trends of today.

The term strategic planning originated in the 1950s and was very popular between the mid1960s and the mid 1970s. During these years, strategic planning was widely believed to be the answer for all problems. At the time, much of the business world was "obsessed" with strategic planning. Following that "boom", however, strategic planning was cast aside during the 1980s as various planning models did not yield higher returns. The 1990s, however, brought the revival of strategic planning, and the process is widely practiced today in the business world.

A strategic plan is, in essence, a company's game plan. Just as a football team needs a good game plan to have a chance for success, a company must have a good strategy plan to compete successfully. Profit margins among firms in most industries have been so reduced that there is little room for error in the overall plan. A strategic plan results from tough managerial choices among numerous good alternatives, and it signals commitment to specific markets, policies, procedures, and operations in lieu of others, "less desirable" courses of action.

The term strategic management is used at many colleges and universities as the subtitle for the capstone course in business administration-Business Policy-which integrates material from all business courses.

\section{Stages of Strategic Management}

The strategic-management process consists of tree stages: strategy formulation, strategy implementation, and strategy evaluation. Strategy formulation includes developing a vision and mission, identifying an organization's external opportunities and threats, determining internal strengths and weaknesses, establishing long-term objectives, genera- ting alternative strategies, and choosing particular strategies to pursue. Strategy- formulation issues include deciding what new business to enter, what business to abandon, how to allocate resources, whether to merge or form a joint venture, and how to avoid a hostile takeover.

Because no organization has unlimited resources, strategists must decide which alternative strategies will benefit the firm most. Strategy-formulation decisions commit an organization to specify products, markets, resources, and technologies over an extended period of time. Strategies determine long-term competitive advantages. For better or worse, strategic decision have major multifunctional consequences and enduring effects on an organization. Top managers have the best perspective to understand fully the ramifications of strategyformulation decisions; they have the authority to commit the resources necessary for implementation.

Strategy implementation requires a firm to establish annual objectives, device policies, motivate employees, and allocate resources so that formulated strategies can be executed. Strategy implementation includes developing a strategy-supportive culture, creating an effective organizational structure, redirecting marketing efforts, preparing budgets, developing and utilizing information systems, and linking employee compensation to organizational performance.

Strategy implementation often is called the "action stage" of strategic management. Implementing strategy means mobilizing employees and managers to put formulated 
strategies into action. Often considered to be the most difficult stage in strategic management, strategy implementation requires personal discipline, commitment, and sacrifice. Successful strategy implementation hinges upon managers' ability to motivate employees, which is more an art than a science. Strategies formulated but not implemented serve no useful purpose.

Interpersonal skills are especially critical for successful strategy implementation. Strategyimplementation activities affect all employees and managers in an organization. Every division and department must decide on answers to questions, such as "What must we do to implement our part of the organization's strategy?" and "How best can we get the job done?" The challenge of implementation is to simulate managers and employees throughout an organization to work pride and enthusiasm toward achieves stated objectives.

Strategy evaluation is the final stage in strategic management. Managers desperately need to know when particular strategies are not working well, strategy evaluation is the primary means for obtaining this information. All strategies are subject to future modification because external and internal factors are constantly changing. Three fundament- al strategy-evaluation activities are (1) reviewing external and internal factors that are the bases for current strategies, (2) measuring performance, and (3) taking corrective actions. Strategy evaluation is needed because success today is no guarantee of success tomorrow! Successful always creates new and different problems; complacent organization experience demise.

Strategy formulation, implementation, and evaluation activities occur at three hi- anarchical levels in a large organization corporate, divisional or strategic business unit, and functional . By fostering communication and interaction among managers and employees across hierarchical levels, strategic management helps a firm function as a competitive team. Most small business and some large business do not have divisions or strategic business units; they have only the corporate and functional levels. Nevertheless, managers and employees at these two levels should be actively involved in strategic-management activities.

Business expert and icon Peter Drucker says the prime task of strategic management in thinking through the overall mission of a business:

......that is, of asking the question, "What is our Business?" This leads to the setting of objectives, the development of strategies, and the making of today's decisions for tomorrow's results. The clearly must be done by a part of the orgeneration that can see the entire business; that can balance objectives and the needs of today against the needs of tomorrow; and that can allocate resources of men and money to key results. ${ }^{1}$

\section{The Strategic-Management Model}

The strategic-management process can best be studied and applied using a model. Every model represents some kind of process. The framework illustrated in figure 1.1. is a widely accepted, comprehensive model of the strategic-management process. ${ }^{2}$ This mod- el does guarantee success, but it does represent a clear and practical approach for formulating, implementing, and evaluating strategies. Relationships, among major components of the strategicmanagement process are shown in the, which appears in all subsequent chapters with appropriate areas shaped to show the particular focus of each chapter. 


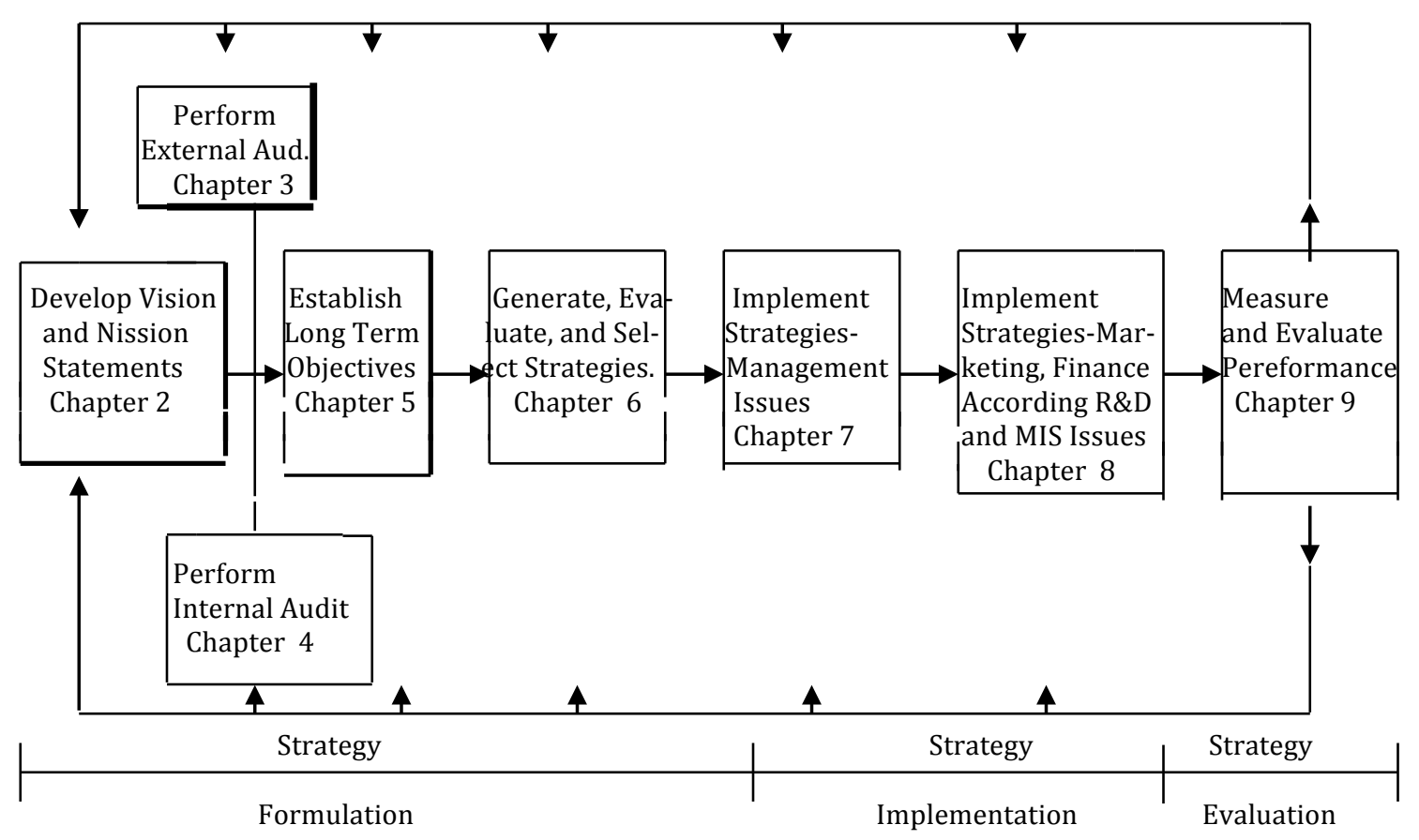

Figure 1.1. A Comprehensive Strategic - Management Model

Source: Fred R. David, “ How Companies Define Their Mission,” Long Range Planning 22, no. 3 (June 1988): 40

Identifying an organization's existing vision, mission, objectives, and strategies is the logical starting point for strategic management because a firm's present situation and condition may preclude certain strategies and may even dictate a particular course of action. Every organization has a vision, mission, objectives, and strategy, even if these elements are not consciously designed, write, or communicated. The answer to where an organization is going can be determined largely by where the organization has been!

The strategic-management process is dynamic and continuous. A change in any of the major components in the model can necessitate in any or all of the other components. For instance, a shift in the economy could represent a major opportunity and require a change in long-term objectives and strategies; a failure to accomplish annual objectives could require a change in the firm's mission. Therefore, strategy formulation, implementation, and evaluation activities should be performed on a continual basis, not just at the end of the year or semi annually. The strategic management process never really ends.

The strategic-management process is not as cleanly divided and neatly performed in practice as the strategic-management model suggests. Strategists do not go through the process in lockstep fashion. Generally, there is give-and-take among hierarchical levels of an organization. Many organizations semi annually conduct formal meetings to discuss and update the firm's vision/mission, opportunities/threats, strengths/weaknesses, strategies, objectives, policies, and performance. These meetings are commonly held off-premises and are called retreats. The rationale for periodically conducting strategic-management meetings away from the work site is to encourage more creativity and candour from participants. Good communication and feedback are needed throughout the strategic participants. Good communication and feedback are needed throughout the strategic management process.

Application of the strategic-management process is typically more formal in larger and wellestablished organizations. Formality, refers to the extent that participants, responsibilities, 
authority, duties, and approach are specified. Smaller businesses tend to be less formal. Firms that compete on complex, rapidly changing environments, such as technology companies, tend to be more formal in strategic planning. Firms that have many divisions, products, markets, and technologies also tend to be more formal in applying strategic-management concepts. Greater formality in applying the strategic-management process is usually positively associated with the cost, comprehensiveness, accuracy, and success of planning across all types and sizes of organizations. ${ }^{3}$

\section{Benefits of Strategic Management}

Strategic management allows an organization to be more proactive than reactive in shaping its own future; it allows an organization to initiate and influence (rather than just respond to) activities - and thus to exert control over its own destiny. Small business owners, chief executive officers, presidents, and managers of many for-profit and non profit organizations have recognized and realized the benefits of strategic management.

Historically, the principal benefit of strategic management has been to help organizations formulate better strategies through the use of a more systematic, logical, and rational approach to strategic choice. This certainly continues to be a major benefit of strategic management, but research studies now indicate that the process, rather than the decision or document, is the more important contribution of strategic management. ${ }^{4}$ Communication is a key to successful strategic management. Through involvement in the process, managers and employees become committed to supporting the organization. Dialogue and participation are essential ingredients.

The manager in which strategic management is carried out is thus exceptionally important. A major aim of then process is to achieve the understanding of and commitment from all managers and employees. Understanding may be the most important benefit of strategic management, followed by commitment. When managers and employees understand what the organization is doing and why, they often feel that they are a part of the firm and become committed to assisting. This is especially true when employees also understand linkages between their own compensation and organizational performance. Managers and employees become surprisingly creative and innovative when they understand and support the firm's mission, objectives, and strategies. A great benefit of strategic management, then, is the opportunity that the process provides to empower individuals. Empowerments is the act of strengthening employee' sense of effectiveness by encouraging them to participate in decision making and to exercise initiative and imagination, and rewarding them for doing so.

More and more organizations are decentralizing the strategic-management process, recognizing that planning must involve lower-level managers and employees. The notion of centralized staff planning is being replaced in organizations by decentralized line-manager planning. For example, Walt Disney Co. recently dismantled its strategic-planning department and gave those responsibilities back to the Disney business divisions. Former CEO Michael Eisner had favoured the centralized strategic-planning approach, but new CEO Robert Iger dissolved Disney's strategic-planning department within weeks of his taking over the top office at Disney. The process is a learning, helping, educating, and supporting activity, not merely a paper shifting activity among the executives. Strategic-management dialogue is more important than a nicely bound strategic-management document. ${ }^{5}$ The worst thing strategists 
can do is develop strategic plans themselves and then present them to operate managers to execute. Through involvement in the process, line managers become "owners" of strategy. Ownership of strategies by the people who have to execute them is a key to success!

Although making good strategic decisions is the major responsibility of an organization's owner or chief executive officer, both managers and employees must also be in- volved in strategy formulation, implementation, and evaluation activities. Participation is a key to gaining commitment for needed changes.

An increasing number of corporations and institutions are strategic management to make effective decisions. But strategic management is not a guarantee for success; it can be dysfunctional if conducted haphazardly.

\section{Business Ethics and Strategic Management}

Business ethics can defined as principles of conduct within organizations that guide decision making and behaviour. Good business ethics is a prerequisite for good strategic management; good ethics is just good business!

A rising tide of consciousness about the importance of business ethics is sweeping the world. Strategists are the individuals primarily responsible for ensuring that high ethical principles are espoused and practiced in an organization. All strategy formulation, implementation, and evaluation decisions have ethical ramifications.

Newspapers and business magazines daily report legal and moral breaches of ethical conduct by both public and private organizations. The biggest pay-outs for class action legal fraud suits ever were against Enron ( $\$ 7,16$ billion),WorldCom $(\$ 6,16$ billion), Cendant ( $\$ 3,53$ billion), Tyco ( $\$ 2,98$ billion) and etc.

Managers and employees of firms must be careful not to become scapegoats blamed for company environmental wrongdoings. Harming the natural environment is unethical, illegal, and costly. When organizations today face criminal charges for polluting the environment, firms increasingly are turning on their managers and employees to win leniency for themselves. Employee firing and demotions are becoming common in pollution-related legal suits. Managers being fired at Darling International, Inc., and Niagara Mohawk Power Corporation for being indirectly responsible for their firms polluting water exemplifies this corporate trend. Therefore, managers and employees today must be careful not to ignore, conceal, or disregard a pollution problem, or they may find themselves personally liable.

A new wave of ethics issues related to product safety, employee health, sexual harassment, AIDS in the workplace, smoking, acid rain, affirmative action, waste disposal, foreign business practices, cover-ups, takeover tactics, conflicts of interest, employee privacy, inappropriate gifts, security of company records, and layoffs has accentuated the need for strategists to develop a clear code of business ethics. A code of business ethics can provide a basis on which policies can be devised to guide daily behaviour and decisions at work site.

Merely having a code of ethics, however, is not sufficient to ensure ethical business behaviour. A code of ethics can be viewed as a public relations gimmick, a set of platitudes or window dressing. To ensure that the code is read, understood, believed, and remembered, organizations need to conduct periodic ethics workshops to sensitize people to workplace 
circumstances in which ethics issues may arise. ${ }^{6}$ If employees see examples of punishment for violating the code and rewards for upholding the code, this helps reinforce the importance of a firm's code of ethics.

An ethics "culture" needs to permeate organizations! To help create an ethics culture, Citicorp developed a business ethics board game that is forty thousand employees in forty-five countries. Called "The World Ethic," this game asks players business ethics questions, such as how do you deal with a customer who offers you football tickets in ex- change for a new, backdated retirement saving account? Diana Robertson at the Wharton School of Business believes the game is effective because it is interactive. Many organizations, such as how to prime Computer and Kmart, have developed a code-of-conduct manual outlining ethical expectations and giving examples of situations that a commonly arise in their business. Harris Corporation's managers and employees are warned that failing to report an ethical violation by others could bring discharge.

One reason strategists' salaries are high compared to those of other individuals in an organization is that strategists must take the moral risks of the firm. Strategists are responsible for developing, communicating, and enforcing the code of business ethics for their organizations. Although primary responsibility for ensuring ethical behaviour rests with a firm's strategists, an integral part of the responsibility of all managers is to provide ethics leadership by constant example and demonstration. Managers hold positions that enable them to influence and educate many people. This makes managers responsible for developing and implementing ethical decision making. Gellerman and Drucker, respectively, offer some good advice for managers:

All managers risk giving too much because of what their companies demand from them. But the same superiors, who keep prising you to do more, or to do it better, or faster, or less expensively, will turn on you should you cross that fuzzy line between right and wrong. They will blame you for exceeding instructions or for ignoring their warnings. The smartest managers already know that the best answer to the question "How far is too far?, is don't try find out. ${ }^{7}$

A man (or woman) might know too little, reform poorly, lack judgement and ability, and yet not do too much damage as a manager. But that person lacks character and integrity-no matter how knowledgeable, how brilliant, how successful - he destroys. He destroys people, the most valuable resource of the enterprise. He destroys spirit. And he destroys performance. This is particularly true of the people at the head of an enterprise. For the spirit of an organization is created from the top. If an organization is great in spirit, it is because the spirit of its top people is great. If it decays, it does so because the top rots. As the proverb has it, "Trees die from the top."No one should ever become a un- less he or she is willing to have his or her character serve as the model for subordinates. ${ }^{8}$

No society anywhere in the world can compete very long or successfully with people stealing from one another or not trusting one another, with every bit of information requiring notarized confirmation, with every disagreement ending up in litigation, or with government 
having to regulate businesses to keep them honest. Being unethical is a recipe for headaches, inefficiency, and waste. History has proven that the greater the trust and confidence of people in the ethics of an institution or society, the greater its economic strength. Business relationships are built mostly on mutual trust and reputation. Short-term decisions based on greed and questionable ethics will preclude the necessary selg respect to gain the trust of others. More and more firms believe that ethics training and an ethics culture create strategic advantage.

Some business actions considered to be unethical include misleading advertising or labelling, coursing environmental harm, poor product or service safety, padding expense accounts, insider trading, dumping banned or flawed products in foreign markets, lack of equal opportunities for women and minorities, overpricing, hostile takeovers, moving jobs overseas, and using non-union labour in a union shop. ${ }^{9}$

Internet fraud, including hacking into company computers and spreading viruses, has become a major unethical activity that plagues every sector on line commerce from banking to shopping sites. More than three hundred Web sites now show individuals how to hack into computers; this problem has become endemic nationwide and around the world.

Ethic training programs should include messages from the CEO emphasizing ethical business practices, the development and discussion of codes of ethics, and procedures for discussing and reporting unethical behaviour. Firms can align ethical and strategic decision making by incorporating ethical considerations into long-term planning, by integrating ethical decision making into the performance appraisal process, by encouraging whistle-blowing or the reporting of unethical practices, and by monitoring departmental and corporate performance regarding ethical issues.

In a final analysis, ethical standards come out of history and heritage. Our predecessors have left us with an ethical foundation to build upon. Even the legendary football coach Vince Lombardi, who coached the U.S. green Bay Packers, knew that some things were worth more than winning, and he required his players to have three kinds of loyalty: to God, to their families, and to the Green Bay Packers," in that order".

\section{The Nature of Global Competition}

For centuries before Columbus discovered America and surely for centuries to come, businesses have searched and will continue to search for new opportunities beyond their national boundaries. There has never been a more internationalized and economically competitive society than today's. Some U.S. industries, such as textiles, steel, and consumer electronics, are in complete disarray as result of the international challenge.

Organizations that conduct business operations across national borders are called international firms or multinational corporations. The term parent company refers to a firm investing in international operations, whole host country is the country where that multinational firms as for purely domestic firms; however, the process is more complex for international firms because of the presence of more variables and relationships. The social, cultural, demographic, environmental, political, governmental, legal, technological, and competitive opportunities and threats that face a multinational corporation are almost 
limitless, and the number and complexity of these factors increase dramatically with the number of produced produced and the number geographic areas served.

More time and effort are required to identify and evaluate external trends and events in multinational corporations than in domestic corporations. geographical distance, cultural and national differences, and variations in business practices often make communication between domestic headquarters and overseas operations difficult. Strategy implementation can be more difficult because different cultures have different norms, and work ethics.

Advancements in telecommunications are drawing countries, cultures, and organizations worldwide closer together. Foreign revenue as a per cent of total company revenues already exceeds 50 per cent in hundreds of U.S. firms, including ExxonMobil, Gillette, Dow Chemical, Citicorp, Colgate-Palmolive, and Rexaco. Unilever had $\$ 10$ billion and $\$ 21,3$ billion in domestic and foreign revenues, respectively, in 2006. A primary reason why most domestic firms are engaging in global operations is that growth in demand for goods and services outside the United States is considerably higher than inside. For example, the domestic food industry is growing just 3 per cent per year, so Kraft foods, the second largest food company in the world behind Nestle, is focusing on foreign acquisitions. Shareholders and investors expect sustained growth in revenues from firms; satisfactory growth for many firms can only be achieved by capitalizing on demand outside their domestic countries. Computer shipments grew 21 per cent in China in 2006, so Dell has greatly expanded its operations in China. Joint ventures and partnerships between domes- tic and foreign firms are becoming the rule rather than the exception!

The line-up competitors in virtually industries today is global. Global competition is more than a management fad. General Motors, Ford, and Shrysler compete with Toyota and Hyundai. General Electric and Westinghouse battle Siemens and Mitsubishi. Caterpillar and John Deerecomete with Komatsu. Goodyear battles Michelin, Bridgestone/Fire- stone, and Pirelli, Boeing competes with Airbus. Only a few U.S. industries - such as furniture, printing, retailing, consumer packaged goods, and retail banking - are not yet greatly challenged by foreign competitors. But many products and components in these industries too are now manufactured in foreign countries.

International operations can be as simple as exporting a product to a single foreign country or as complex as operating manufacturing, distribution, and marketing facilitates in many countries. Firms are acquiring foreign companies and forming joint ventures with them and vice versa. This trend is accelerating dramatically. International expansion is no guarantee of success, however.

\section{Advantages and Disadvantages of International Operations}

Firms have numerous reasons for formulating and implementing strategies that initiate, continue, or expand involvement in business operations across natural borders. Perhaps the greatest advantage is that firms can gain new customers for their products and services, the greatest advantage is the firms can gain new customers for for their products and services, thus increasing revenues. Growth in revenues and profits is a common organizational objective and often an expectation if shareholders because it is a measure of organizational success.

In addition to seeking growth, firms have the following potentially advantages re- asons to initiate, continue, and expand international operations: 
1. Foreign operations can absorb excess capacity, reuce unit costs, and spread economics risks over a wider number of markets.

2. Foreign operations can allow firms to establish low-cost production facilities in locations close to raw materials and/or cheap labour.

3. Competitors in foreign markets not exist, or competition may be less intense than in domestic markets.

4. Foreign operations may result in reduced tariffs, lower taxes, and favourable political treatment in other countries.

5. Joint ventures can enable firms to learn the technology, culture, and business pracitors of other people and to make contacts with potential customers, suppliers, creditors, and distributors in foreign countries.

6. Many foreign governments and countries offer varied incentives to encourage foreign investment in specific locations.

7. Economies of scale can be achieved from operation in global rather than solely domestic markets. Larger-scale production and better efficiencies allow higher sales volumes and low-price offerings.

A firm's power and prestige in domestic markets may be significantly enhanced with various stakeholder groups if the firm competes globally. Enhanced prestige can translate into improved negotiating power among creditors, suppliers, distributors, and other important groups.

There are also numerous potential disadvantages of initiating, continuing, or expanding business across national borders. One risk is that foreign operations could be seized by nationalistic factions. Other disadvantages include the following:

1. Firms confront different and often little-understood social, cultural, demographic, environmental, political, governmental, legal, technological, economic, and competitive forces when internationally doing business. These forces can make communication difficult between the parent firm an subsidiaries.

2. Weaknesses of competitors in foreign lends are often overestimated, and strengths are often underestimated. Keeping informed about the number and nature of competitors is more difficult when internationally doing business.

3. Language, culture, and value systems differ among countries, and this can create barriers to communication an problems managing people.

4. Gaining an understanding of regional organizations such as the European Economic Community, the Latin American Free Trade Area, the Intentional Bank for Reconstruction and envelopment, and the International Finance Corporation is difficult but often required in internationally doing business.

5. Dealing with two or more monetary systems can complicate international business operations.

6. The availability, depth, and reliability of econimic and marketing information in different countries vary extensively, as do industrial structures, business practices, and the number and nature of regional organizations.

\section{Conclusion}

All firms have a strategy, even if it is informal, unstructured, and sporadic. All organizations are evading somewhere, but unfortunately some organizations do not know where they are going. The old saying "If you do not know where you are going, then any road will lead you there!" accents the need for organizations to use strategic-management concepts and techniques. The strategic-management process is becoming more widely used by small firms, large companies, 
non-profit institutions, governmental organizations, and multinational conglomerates alike. The process of empowering managers and employees has almost limitless benefits.

Organizations should take a proactive rather than a reactive approach in their industry, and they should strive to influence, anticipate. and initiate tarher than just respond to events. The strategic-management process embodies this approach to decision making. It represents a logical, systematic, and objective approach for determining an enterprise's future direction. The stakes are generally too high for strategists to use intuition alone in choosing among alternative courses of action. Successful strategists take the time to think about their businesses, where they are with their business, and what they want to be as organizations and then they implement programs and policies to get from where they are to where they want to be in a reasonable period of time. It is a known and accepted fact that people and organizations that plan ahead are much more likely to become what they want to became than those that do not plan at all. A good strategist plans and control is his or her plans, while a bad strategist never plans and then tries to control people!

Success in business increasingly depends upon offering products and services that are competitive on a world basic, not just on a local basic. If the price and quality of a firm's products and services are not competitive with those available elsewhere in the world, the firm may soon face extinction. Global markets have become a reality in all but the most remote areas of ye world. Certainly throughout the United States, even in small towns, firms feel the pressure of world competitors. Nearly half of all automobiles sold in the United States, for example, are in Japan and Germany.

\section{Notes}

1 Peter Drucker, Management Tasks, Responsibilities, and Practices (New york: Harper \&Row, 1974); 611.

2 Fred R. David, “How Companies Define Their Mission,” Long Range Planning 22. no 1 (February 1989); 91.

3 Jack Pearce and Richard Robinson, "Strategies Management, " 7th ed. (New York; McGrawHill, 2000); 8.

4 Ann langley,"The Roles of Formal Strategic Planning," Long Range Planning 21, no. 3 (June 1988): 40.

5 Bernard Reimann, “Getting Value from Strategic Planning.” Planning Review 16, no, 3 (MayJune 1988): 40.

6 Joann Greco, "Privacy - Whose Right Is It Anyhow?” Journal of Business Strategy (JanuaryFebruary 2001); 32.

7 Saul Gellerman, “Why 'Good' Managers Make Bad Ethical Chices”, Harvard Business Review 64, no. 4 (July-August 1986); 88.

8 Drucker, 462, 463.

9 Gene Lacznaik, Marvin Berkowitz, Russell Brooker, and James Hale,"The Ethics of Bisiness: Improving or Deteriorating?" Business Horizons 38, no. 1 (January-February 1995): 43. 